\title{
Susceptibilty Testing of Candida spp. Strains to Ketoconazole Using Minimum Inhibitory Concentration Strip Test
}

\author{
George Cosmin NADĂȘ*, Nicodim FIŢ, Flore CHIRILĂ, Cosmina BOUARI, Sorin RĂPUNTEAN \\ University of Agricultural Sciences and Veterinary Medicine Cluj-Napoca, Faculty of Veterinary Medicine, \\ 3-5 Mănăştur Street, 400372, Romania \\ *Corresponding author: gnadas@usamvcluj.ro
}

Bulletin UASVM Veterinary Medicine 72(2) / 2015,

Print ISSN 1843-5270; Electronic ISSN 1843-5378

DOI:10.15835/buasvmcn-vm: 11589

\begin{abstract}
Candida spp. infections in animals are becoming problematic and very frequent in the last decades. Antimycotic treatment is usually successful, but recently common cases of resistance are recorded. Minimum inhibitory concentration (MIC) test strips is a quantitative assay for determining the MIC of antimicrobial agents against microorganisms to indicate appropriate patient treatment and for identifying resistance patterns.

The aim of this paper was the susceptibility testing of Candida strains isolated from animals in the area of ClujNapoca to ketoconazole, using MIC strip technique.

Materials and methods: A total number of twenty-three Candida spp. strains isolated from both humans and animals were suspended in saline, and $1 \mathrm{ml}$ of the resulted suspension ( $0.5 \mathrm{McF}$ arland scale) was used to flood the Sabouraud Dextrose agar Petri dish. The suspension was then removed and the strip was placed in the middle of the plate. The incubation was performed at $28^{\circ} \mathrm{C}$ for 48 hours. When the strip is applied onto an inoculated agar surface, the preformed exponential gradient of antimicrobial agent is transferred into the agar matrix.

The MIC is read directly from the scale in terms of $\mu \mathrm{g} / \mathrm{ml}$, at the point where the edge of the inhibition ellipse intersects with the MIC Test Strip. MIC for the 23 Candida spp. tested strains varied between 0.002 and $8 \mu \mathrm{g} / \mathrm{ml}$, with an average of $3.6 \mu \mathrm{g} / \mathrm{ml}$.

Susceptibility testing of 23 Candida spp. isolates from Cluj-Napoca area to ketoconazole using the MIC strips is an accurate, simple, fast and accessible quantitative method, recommend for diagnostic in microbiological laboratories.
\end{abstract}

Keywords: antimycotic, Candida spp., ketoconazole, MIC strip test

\section{INTRODUCTION}

Candida spp. infections in animals are becoming problematic and very frequent in the last decades. Candidiasis is a localized mucocutaneous disease caused by species of the yeast-like fungus Candida, most commonly $C$. albicans. It is distributed worldwide in a variety of animals. C. albicans is a normal inhabitant of the nasopharynx, gastrointestinal tract, and external genitalia of many species of animals and is opportunistic in causing disease. Factors associated with candidal infections are disruption of mucosal integrity; indwelling, intravenous, or urinary catheters; administration of antibiotics; and immunosuppressive drugs or diseases (3).

Antimycotic treatment is usually successful, but recently common cases of resistance are recorded. Minimum inhibitory concentration (MIC) test strips is a quantitative assay for determining the MIC of antimicrobial agents against microorganisms to indicate appropriate patient treatment and for identifying resistance patterns.

The aim of this paper was the susceptibility testing of Candida strains isolated from animals in the area of Cluj-Napoca to ketoconazole using 
MIC strip technique, for an efficient and precise recommendation of the mentioned antimycotic.

\section{MATERIALS AND METHODS}

A total number of twenty-three Candida spp. strains isolated from both humans and animals were suspended in saline, and $1 \mathrm{ml}$ of the resulted suspension (0.5 McFarland scale) was used to flood the Sabouraud Dextrose agar Petri dish. The excess suspension was then removed, the agar surface was allowed to dry and the strip was placed in the middle of the plate. The incubation was performed at $28^{\circ} \mathrm{C}$ for 48 hours. When the strip is applied onto an inoculated agar surface, the preformed exponential gradient of antimicrobial agent is transferred into the agar matrix.

\section{RESULTS AND DISCUSSION}

The MIC is read directly from the scale in terms of $\mu \mathrm{g} / \mathrm{ml}$, at the point where the edge of the inhibition ellipse intersects with the MIC Test Strip. MIC for the 23 Candida spp. tested strains varied

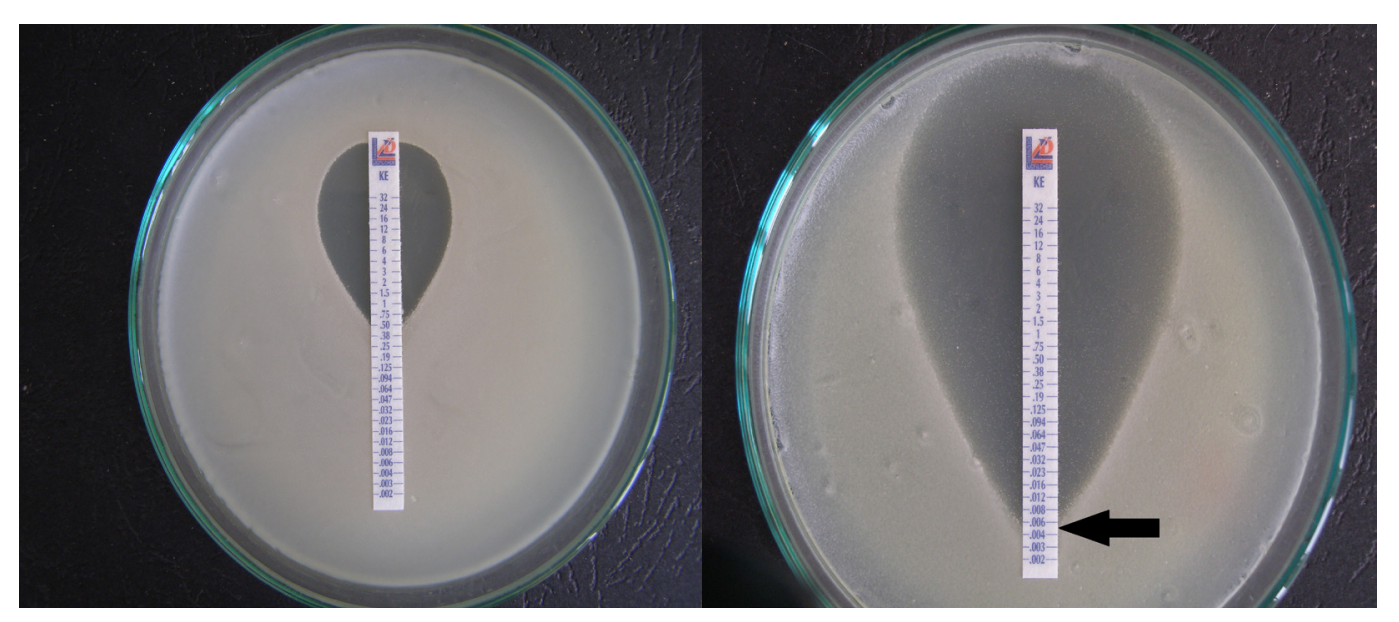

Fig. 1. The results for MIC determination using Ketoconazole strips - the values are $5 \mu \mathrm{g} / \mathrm{ml}$ and $0.006 \mu \mathrm{g} / \mathrm{ml}$ respectively.

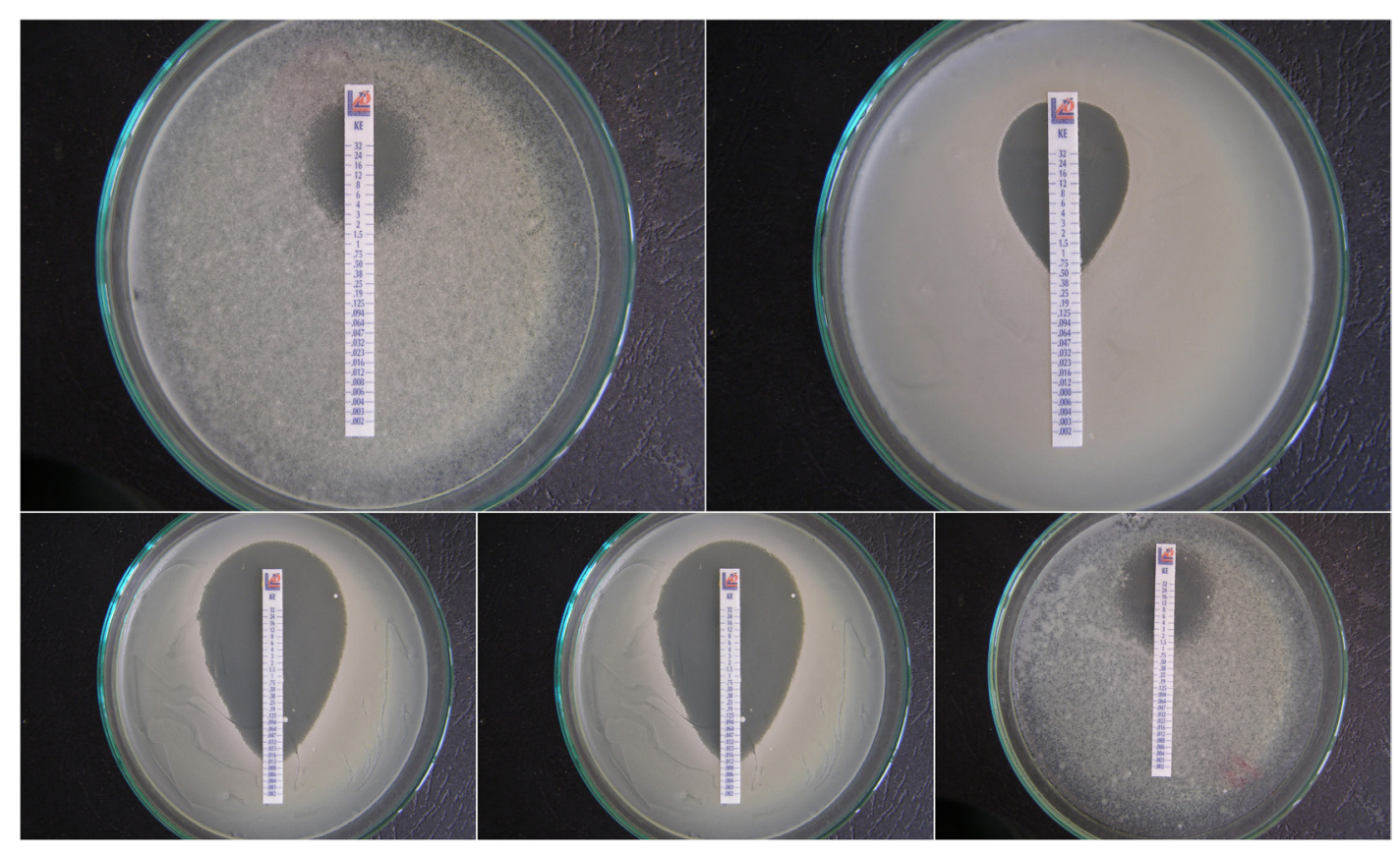

Fig. 2. The results for MIC determination using Ketoconazole strips - the values are different, according to the antimycotic susceptibility. 
between 0.002 and $8 \mu \mathrm{g} / \mathrm{ml}$, with an average of 3.6 $\mu \mathrm{g} / \mathrm{ml}$.

In Fig. 2, the MIC values are $3 \mu \mathrm{g} / \mathrm{ml}, 0.5 \mu \mathrm{g} /$ $\mathrm{ml}, \quad 0.012 \mu \mathrm{g} / \mathrm{ml}, \quad 0.016 \mu \mathrm{g} / \mathrm{ml}$ and $1.5 \mu \mathrm{g} / \mathrm{ml}$ respectively. This study evaluated Candida strains isolated from Cluj County susceptibility to antimycotics and the results are generally similar with other researches in the field. The only important difference is represented by the fact that current susceptibility is decreased compared to the results obtained $10-15$ years ago. Our results average was $3.6 \mu \mathrm{g} / \mathrm{ml}$ compared to 10 and $20 \mu \mathrm{g} /$ $\mathrm{ml}$ most frequently obtained at that time.

\section{CONCLUSION}

Susceptibility testing of 23 Candida spp. isolates from Cluj-Napoca area to ketoconazole using the MIC strips test led to the following conclusions:

-Susceptibility testing to ketoconazole demonstrated a good overall sensitivity, with a MIC average of $3.6 \mu \mathrm{g} / \mathrm{ml}$.

-The overall susceptibility of the tested strains average value is lower compared to similar strains previously tested (10 and $20 \mu \mathrm{g} / \mathrm{ml})$ and demonstrates an increased efficiency of ketoconazole for the strains isolated in Cluj County.

-MIC strip test is a modern alternative to the classic test tubes or micro well plate with the major advantage of the interpretation procedure.

\section{REFERENCES}

1.Koehling HL, Willinger B, Buer J, Rath PM, Steinmann JJ (2014). Comparative evaluation of a new commercial colorimetric microdilution assay (SensiQuattro Candida EU) with MIC test strip and EUCAST broth microdilution methods for susceptibility testing of invasive Candida isolates. Clin Microbiol 53(1):255-61. doi: 10.1128/ JCM.02830-14.

2.http://www.liofilchem.net/en/mov_mic_ test_strip.php.

3.http://www.merckvetmanual.com/mvm/ generalized_conditions/fungal_infections/ candidiasis.html. 